\title{
Língua Portuguesa para imigrantes e refugiados: relato de uma experiência no IFRS - Campus Bento Gonçalves
}

\author{
Carina Fior Postingher Balzan ${ }^{1}$ \\ Andréia Kanitz ${ }^{2}$
}

\begin{abstract}
Resumo
0 texto relata a experiência vivenciada no Curso de Extensão Língua Portuguesa para imigrantes e refugiados no IFRS - Campus Bento Gonçalves. A partir do ano de 2010, o Brasil tornou-se o destino de milhares de pessoas que foram forçadas a deixar seu país de origem motivadas por desastres naturais, instabilidade política $e$ econômica, conflitos e guerras. Para esses migrantes, o aprendizado da língua portuguesa constitui fator determinante para a inserção na sociedade brasileira. A partir da concepção teórica de língua de acolhimento, 0 IFRS - Campus Bento Gonçalves oferta um curso específico para imigrantes e refugiados, com o objetivo de promover um aprendizado da língua portuguesa que permita aos sujeitos comunicar-se em situações cotidianas de interação social, procurar trabalho, acessar os serviços públicos de saúde e educação e, progressivamente, exercerem sua cidadania. Abordamos o conceito de língua de acolhimento, com base nos pressupostos de Amado (2014), Grosso (2010), São Bernardo (2016), Barrantes (2015) e Costa (2017); descrevemos a configuração do referido curso, objetivos e estratégias de ensino desenvolvidas. Por fim, trazemos alguns dados a respeito da crescente demanda pelo curso e evidenciamos a importância dessa ação de extensão junto ao público atendido.
\end{abstract}

Palavras-chave: Imigrantes e refugiados. Ensino de Língua Portuguesa. Língua de Acolhimento.

Resumen

El texto informa la experiencia del Curso de Extensión de Lengua Portuguesa para inmigrantes y refugiados en el IFRS - Campus Bento Gonçalves. A partir de 2010, Brasil se convirtió en el destino de miles de personas que se vieron obligadas a abandonar su país de origen motivadas por desastres naturales, inestabilidad política y económica, conflictos y guerras. Para estos migrantes, aprender el idioma portugués es un factor determinante para la inserción en la sociedad brasileña. Basado en la concepción teórica de lengua de acogida, el IFRS Campus Bento Gonçalves ofrece un curso específico para inmigrantes y refugiados, con el objetivo de promover un aprendizaje del idioma portugués que permita a los sujetos comunicarse en situaciones cotidianas de interacción social, para buscar acceder a los servicios de salud pública y educación y ejercer progresivamente su ciudadanía. Abordamos el concepto de lengua de acogida, basado en los supuestos de Amado (2014), Grosso (2010), São Bernardo (2016), Barrantes (2015) y Costa (2017); Describimos la configuración de ese curso, los objetivos y las estrategias de enseñanza desarrolladas. Finalmente, traemos algunos datos sobre la creciente demanda del curso y mostramos la importancia de esta acción de extensión con el público servido.

Palabras-clave: Inmigrantes y refugiados. Enseñanza de Lengua Portuguesa. Lengua de Acogida.

\section{Introdução}

A partir do ano de 2010, o Brasil passou a receber imigrantes de várias nacionalidades

\footnotetext{
1 Doutora em Letras. Instituto Federal do Rio Grande do Sul - Campus Bento Gonçalves. E-mail: carina.balzan@bento.ifrs.edu.br

2 Mestre em Letras. Instituto Federal do Rio Grande do Sul - Campus Bento Gonçalves. E-mail: andreia.kanitz@bento.ifrs.edu.br
} 
que, por motivos relacionados a desastres naturais, guerras ou instabilidade política e econômica, deixaram o país de origem e vieram buscar aqui acolhimento, asilo humanitário ou refúgio. Muitos desses imigrantes, principalmente, haitianos, senegaleses $e$, mais recentemente, venezuelanos, escolheram o Rio Grande do Sul para recomeçarem a vida, atraídos pela oferta de trabalho e acesso aos serviços públicos de saúde e educação.

O município de Bento Gonçalves é um dos que mais recebe imigrantes haitianos no Rio Grande do Sul, chegando, em 2019, a mais de mil pessoas, segundo dados da Secretaria de Assistência Social, sendo que 700 fazem parte do Cadastro Único³ (BENTO GONÇALVES, 2019). Um dos primeiros objetivos dos imigrantes que chegam ao município é conseguir um trabalho que lhes permita sobrevier e, ainda, auxiliar os familiares que ficaram no país de origem. A aprendizagem da língua portuguesa torna-se, assim, uma necessidade emergencial para essas pessoas que, sem condições financeiras para pagar um curso em escolas de idiomas, recorrem a centros sociais e associações de apoio a imigrantes que, de forma voluntária e assistemática, promovem um primeiro contato com a língua.

Apesar de o Brasil ser, historicamente, um país formado por imigrantes, não existem, até o momento, políticas públicas para o ensino de língua portuguesa para imigrantes e refugiados. De acordo com Amado (2014), há um grande vácuo no ensino de português como língua de acolhimento para os estrangeiros que chegam ao Brasil em situação de miséria moral e, muitas vezes, com pouquíssimos recursos financeiros.

O Instituto Federal de Educação, Ciência e Tecnologia do Rio Grande do Sul (IFRS) Campus Bento Gonçalves, atento às demandas da comunidade e ciente de sua responsabilidade social, oferta, desde 2013, um Curso de Extensão de Língua Portuguesa voltado especificamente a imigrantes e refugiados, reafirmando seu compromisso junto à sociedade enquanto instituição pública e gratuita.

O presente texto pretende, portanto, relatar a experiência do Curso de Língua Portuguesa para imigrantes e refugiados desenvolvido no IFRS - Campus Bento Gonçalves, baseado na concepção teórica de língua de acolhimento. A seguir, discutimos o conceito de língua de acolhimento a partir dos pressupostos teóricos de Amado (2014), Grosso (2010), São Bernardo (2016), Barrantes (2015) e Costa (2017); apresentamos a configuração do

\footnotetext{
${ }^{3} 0$ Cadastro Único para Programas Sociais, vinculado à Assistência Social, é um banco de dados que identifica e caracteriza famílias de baixa renda (famílias com renda mensal de até 03 salários mínimos ou $1 / 2$ salário mínimo per capita) para potencial acesso a programas sociais.
} 
referido curso, seus objetivos e como se desenvolve o processo de ensino e aprendizagem; e finalizamos evidenciando os resultados percebidos em relação à integração dos participantes do curso na comunidade de fala, evidenciando a importância dessa ação de extensão junto ao público atendido.

2 A Língua Portuguesa enquanto língua de acolhimento

A língua de acolhimento refere-se à aprendizagem de uma língua não materna em contextos de migração, sendo seu objetivo principal a integração dos sujeitos migrantes à sociedade de acolhimento. De acordo com Costa (2017), o público-alvo da língua de acolhimento são imigrantes e refugiados:

[...] transplantados em outros territórios, provenientes de regiões em situação de precariedade econômica, política ou social, cujas possibilidades de (sobre)vivência encontram-se negativamente mais complexas que as dos países receptores, impossibilitando uma vida em condições seguras (COSTA, 2017, p. 244).

Soma-se, ainda, a essa mobilidade forçada a fragilidade das escolhas realizadas no percurso de migração, um processo geralmente feito em caráter de urgência e sem muito planejamento (COSTA, 2017). Assim, os imigrantes chegam ao novo país em situação de vulnerabilidade social, normalmente com recursos financeiros escassos e desgastados pelo processo migratório, condição agravada ainda mais pelo rompimento dos laços familiares, linguísticos e culturais.

Ao chegarem ao país de acolhimento, esses imigrantes enfrentam dificuldades de toda ordem na tentativa de estabelecerem-se na nova sociedade: procurar moradia, conseguir trabalho, adaptar-se ao clima e à cultura local, sem contar com a questão do preconceito étnico-racial, que em algumas regiões do Brasil ainda é presente. 0 maior obstáculo para essa integração, no entanto, está na questão linguística, pois a grande maioria desses imigrantes chega ao Brasil com pouco ou nenhum domínio da língua portuguesa.

De acordo com Amado (2014), o ensino de português como língua estrangeira (PLE) no Brasil apresentou um movimento crescente nos últimos anos, com a criação de cursos de PLE em escolas de idiomas e de cursos de extensão à comunidade acadêmica nas universidades. No entanto, o público a que esses cursos se destinam não contempla as milhares de pessoas que são forçadas a deixar seu país de origem para recomeçarem a vida 
no Brasil, talvez para nunca mais retornarem. Outro fator relevante é que a grande maioria desses imigrantes e refugiados não possui recursos financeiros para pagar por um curso de português em uma escola particular. Assim, além de não terem apropriação do idioma, muitos não conhecem a cultura do país de acolhimento, o funcionamento dos serviços públicos, das leis trabalhistas, o que gera insegurança e medo, e, consequentemente, inibe as tentativas de interação com os brasileiros.

O aprendizado da língua portuguesa como língua de acolhimento (PLAc) torna-se, então, o primeiro passo para a efetiva inclusão social desses sujeitos, para a construção da cidadania e para a reconstrução da própria identidade. Tal conceito vai além da perspectiva linguística e cultural e refere-se também ao caráter emocional e subjetivo da língua e à relação conflituosa presente no contato inicial do imigrante com a sociedade de acolhimento (SÃO BERNARDO, 2016).

Nessa concepção, apropriar-se da língua oficial do novo país possibilita ao imigrante compreender e ser compreendido, isto é, permite-lhe incluir-se no país de acolhimento, pois, como afirma Barrantes (2015, p. 128), “um conhecimento básico da língua, história e instituições do país anfitrião é indispensável para a integração, e possibilitar que os imigrantes adquiram este conhecimento básico é essencial para uma integração exitosa".

O ensino da língua portuguesa como língua de acolhimento, além dos conhecimentos linguísticos, deve priorizar a especificidade de seu público. A própria denominação sugere um olhar voltado ao ser humano, no sentido de "acolher" as diferenças, de respeitar as características de cada um e de valorizar sua cultura, em uma postura de empatia e alteridade. Como aponta Costa (2017), a língua de acolhimento promove a abertura para a diferença e a diversidade no Brasil, dada pela riqueza apresentada nos cursos devido à heterogeneidade linguística e cultural dos alunos.

Nesse sentido, os docentes que atuam em cursos de língua de acolhimento precisam desenvolver sua sensibilidade em relação ao outro, precisam estar abertos para a heterogeneidade característica das turmas, tanto em nível de conhecimentos, quanto em nível de aprendizagens, e, no encontro com o diferente, estar dispostos a também aprender. Como aponta Costa (2017):

Com relação aos professores de PLAc, procura-se que seja um profissional sensível e aberto a diferenças socioculturais, que tenha desenvoltura para trabalhar em ambientes multirraciais e multiétnicos, que entenda bem a necessidade de se 


\section{LÍNGUATEC}

praticar a alteridade, tendo bem desenvolvida sua competência intercultural $\mathrm{e}$ comunicacional, uma vez que os participantes dos cursos de PLAc formam grupos de grande diversidade linguística e cultural (COSTA, 2017, p. 245).

Algumas universidades que promovem cursos de língua portuguesa voltados a imigrantes e refugiados estão desenvolvendo material didático em forma de cadernos e apostilas, disponibilizados na internet de forma pública. Esses materiais têm sido utilizados por docentes de todo Brasil como material de apoio para os cursos. No entanto, devido às especificidades de cada região que recebe os imigrantes e à heterogeneidade dos grupos (nacionalidade, idade, sexo, escolaridade), torna-se necessário desenvolver uma abordagem didática própria, ora adaptando o material já existente, ora criando estratégias de ensino adequadas ao grupo atendido, visto que, como se trata de uma experiência inédita no Brasil, ainda há carência de pesquisas sobre o processo de ensino-aprendizagem de português como língua de acolhimento, como também sobre metodologias e estratégias de ensino eficazes.

\section{Língua Portuguesa para imigrantes e refugiados no IFRS - Campus Bento Gonçalves}

O IFRS - Campus Bento Gonçalves, desde 0 ano de 2013, realiza ações de extensão de língua portuguesa voltadas para estrangeiros, tendo como público-alvo imigrantes. Em 2018, após uma reformulação teórica e metodológica com base na perspectiva de língua de acolhimento, o curso altera também a sua nomenclatura, que passou de "Língua portuguesa e cultura brasileira para estrangeiros", para "Língua Portuguesa para imigrantes e refugiados", mais condizente com o público a que se destina.

O objetivo do curso é promover um aprendizado da língua portuguesa que permita aos sujeitos comunicar-se em situações cotidianas de interação social como: apresentar-se, pedir informações, locomover-se pela cidade, fazer compras, procurar emprego, providenciar documentação, acessar os serviços públicos de assistência social, saúde e educação. Cabe mencionar que este é o único curso da região da Serra Gaúcha voltado a imigrantes e refugiados oferecido por uma instituição pública e, portanto, totalmente gratuito.

O Curso de Língua Portuguesa, de nível básico, é oferecido no formato presencial, em dois módulos: Módulo I, que prioriza conhecimentos basilares da língua portuguesa que permitam a comunicação oral dos sujeitos em situações cotidianas de interação; e Módulo II, em que o conhecimento da língua escrita é aprofundado a partir de leitura e compreensão de 
textos de diferentes gêneros que circulam socialmente e de produção de pequenos textos, observando as normas gramaticais da língua portuguesa. Cada módulo tem carga horária de 30 horas, e as aulas ocorrem uma vez por semana no Campus Bento Gonçalves, no turno da noite, ministradas por docentes de língua portuguesa do quadro efetivo do IFRS, com experiência no ensino de línguas para estrangeiros. A avaliação dos estudantes é realizada de forma contínua por meio da participação e interesse nas atividades propostas e através do acompanhamento individual das habilidades comunicativas dos alunos.

A proposta metodológica para o ensino da língua está intrinsecamente vinculada ao contexto de uso, priorizando as reais necessidades do grupo, a fim de que os sujeitos possam enfrentar as mais diversas situações cotidianas de interação social. De acordo com Grosso (2010), os conteúdos trabalhados com os imigrantes na perspectiva da língua de acolhimento devem estar ligados a assuntos que mostrem o cotidiano no qual vivem, em situação de contato com a língua e a cultura alvo, que tratem de situações profissionais, culturais, interpessoais etc., e que as atividades sejam baseadas em situações-problema. Nesse sentido, no Curso de Extensão do IFRS - Campus Bento Gonçalves, não há uma apostila ou material definitivo que é utilizado ao longo do curso. Os conteúdos são desenvolvidos de acordo com as demandas de cada turma, do nível de escolaridade e de compreensão da língua portuguesa que possuem $\mathrm{e}$ dos assuntos de interesse manifestados pelos participantes. Alguns materiais didáticos servem de apoio para o planejamento das aulas, como a Cartilha Pode Entrar(2015), da Agência da ONU para refugiados (Acnur), o Caderno Língua Portuguesa para haitianos (2014), do SESI de Santa Catarina, os livros Novo Avenida Brasil I, Novo Avenida Brasil // e Falar, Ler, Escrever: um curso para estrangeiros, da Editora Pedagógica e Universitária Ltda. (EPU). No entanto, dadas as especificidades de cada contexto, como foi dito, esses recursos são aproveitados em parte e os conteúdos adaptados.

As aulas ocorrem de forma expositiva e dialogada, enfatizando a interação entre professor e estudantes e o incentivo para que o aluno participe ativamente do processo, assumindo a posição de protagonista de sua aprendizagem. Daí a importância de se criar um ambiente favorável à participação dos alunos, baseado em uma relação de amizade e confiança entre os sujeitos. De acordo com Grosso (2010), a língua de acolhimento promove um importante elo afetivo entre o professor e o estudante, que se transforma em uma forma de interação linguística para o imigrante. Recursos didáticos como audiovisuais, músicas, panfletos publicitários e material impresso são utilizados com frequência para aproximar os 
estudantes da língua portuguesa em suas manifestações oral e escrita.

Nas primeiras aulas do Módulo I, quando os imigrantes e refugiados ainda estão bastante tímidos na relação com o docente, trabalha-se pequenos diálogos, que iniciam o processo de interação com os brasileiros, como a apresentação pessoal (nome, idade, nacionalidade, estado civil, composição familiar, características físicas, profissão, etc.) e, no decorrer das semanas, passa-se progressivamente para a ampliação de vocabulário e formação de frases envolvendo também a conjugação verbal. Nessa fase inicial, muitas vezes, o docente busca auxílio em outra língua, como francês, inglês ou espanhol, a fim de facilitar a compreensão dos alunos. Assim que os participantes se sentem mais à vontade e confiantes em relação ao idioma, eles próprios vão sugerindo temas a serem trabalhados. Geralmente esses temas estão voltados a aspectos semânticos e morfossintáticos da língua portuguesa, a curiosidades sobre a cultura brasileira, envolvendo conhecimentos da história do Brasil e da região onde residem.

No encerramento de cada Módulo, ao final do semestre, realiza-se uma confraternização entre as turmas do Curso, com comes e bebes, o que configura mais um momento importante de integração e interação entre professores e estudantes. Nesses momentos de descontração, evidencia-se o quanto esses imigrantes se sentem à vontade na Instituição, como se sentem pertencentes à comunidade escolar, usufruindo de um espaço em que são realmente respeitados e valorizados enquanto sujeitos e cidadãos. Na ocasião, também são entregues os certificados de conclusão de curso aos participantes, com a presença da Direção de Extensão do IFRS-Campus Bento Gonçalves. As Figuras I e 2 mostram a entrega dos certificados para os concluintes dos Módulos I e II, no segundo semestre de 2019, durante a confraternização de encerramento do Curso. 


\section{ILIÍNGUATEC}

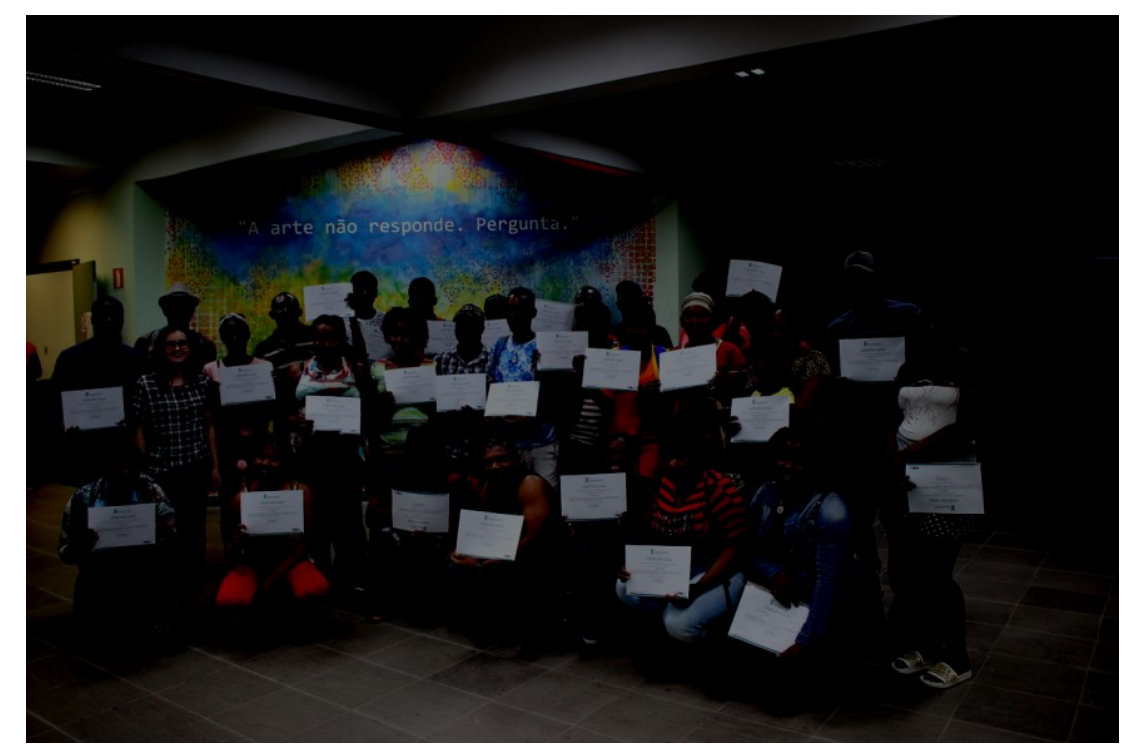

Figura 1: Turma do Módulo I.

Fonte: Arquivo pessoal.

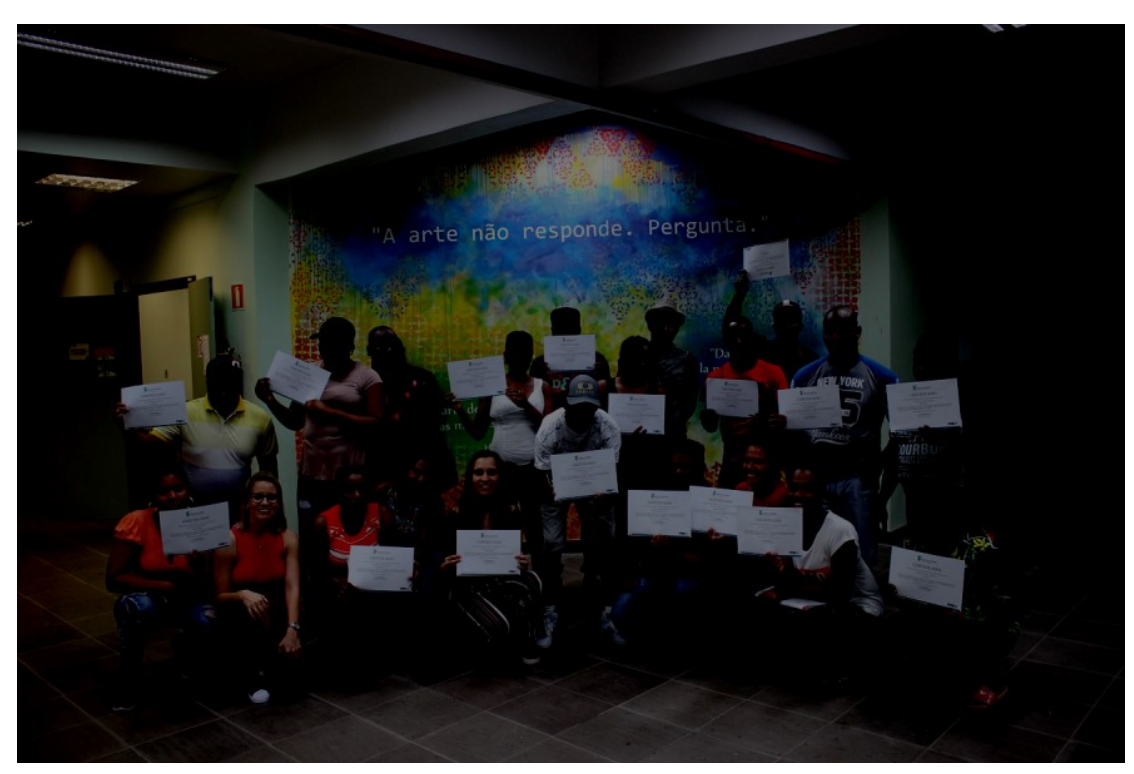

Figura 2: Turma do Módulo II. Fonte: Arquivo pessoal.

Entendemos que o certificado constitui um documento importante para esses imigrantes, principalmente no momento em que batalham por uma vaga no mercado de trabalho. Assim, fazemos da entrega do certificado um momento especial para os concluintes do Curso, como forma de valorizar o seu esforço e dedicação. A certificação de um curso de língua portuguesa para sujeitos em contexto de imigração já é uma conquista. 
40 Curso de extensão em números

Desde 0 início das ações de extensão direcionadas a imigrantes e refugiados, foram atendidas no IFRS-Campus Bento Gonçalves mais de 300 pessoas, de diversas nacionalidades. A grande maioria são haitianos, mas também realizaram o curso pessoas vindas da Venezuela, México, República Dominicana, Iraque, Bangladesh, Paquistão e Sudão.

De 2013 a 2017, quando o curso denominava-se “Língua portuguesa para estrangeiros e cultura brasileira", o número de concluintes foi de 147 pessoas. A partir do segundo semestre de 2018, quando houve a reestruturação teórica e metodológica do curso, passado para a denominação de "Língua Portuguesa para imigrantes e refugiados”, até dezembro de 2019, foram 152 concluintes. Percebeu-se uma redução significativa da evasão após a reestruturação do curso, com um percentual de $15 \%$ atualmente, constituindo um resultado positivo para esse público-alvo. A maior parte dos casos de evasão ocorre por motivo de trabalho, ou seja, os estudantes conseguem um trabalho no turno noturno, o que impede que deem continuidade ao curso.

No primeiro semestre de 2020, estão ocorrendo três turmas de Módulo I do nível básico, totalizando 120 estudantes matriculados. Devido à crescente demanda, optou-se em oferecer temporariamente apenas o primeiro módulo, oportunizando a um maior número de pessoas o aprendizado básico da língua portuguesa. Assim que a demanda pelo Módulo I for reduzida, serão ofertadas novas turmas de Módulo II.

Apesar da oferta de três turmas no primeiro semestre de 2020, já existem mais de 60 pessoas inscritas para as turmas do segundo semestre de 2020 e há uma lista de espera para 0 ano de 2021, o que revela a grande demanda pelo Curso por parte de imigrantes e refugiados de Bento Gonçalves e de municípios do entorno. Vários motivos podem ser apontados para justificar esse aumento da procura pelo Curso, dentre eles, a chegada contínua de novos imigrantes ao Rio Grande do Sul, a necessidade de um aprendizado formal da língua para a comunicação e para o ingresso no mercado de trabalho e, talvez a de maior impacto, a exigência, pela Polícia Federal, de um certificado de língua portuguesa para dar início ao processo de solicitação de naturalização brasileira. De acordo com a Portaria Interministerial $n^{0} 16$, de 03 de outubro de 2018, do Ministério da Justiça e Segurança Pública, exige-se para a solicitação de naturalização brasileira para estrangeiros: 
[...] d) conclusão de curso de idioma português direcionado a imigrantes realizado em instituição de ensino superior reconhecida pelo Ministério da Educação; ou e) aprovação em avaliação da capacidade de comunicação em língua portuguesa aplicado por instituição de ensino superior reconhecida pelo Ministério da Educação na qual seja oferecido curso de idioma mencionado na alínea "d"; (POLÍCIA FEDERAL, 2019).

Essa nova exigência tem motivado um número considerável de estrangeiros que residem no Brasil há alguns anos e que já possuem um bom domínio da língua portuguesa a procurarem o Curso no IFRS-Campus Bento Gonçalves com o objetivo de obterem a certificação, já que a oferta, pública e gratuita, atende à demanda de imigrantes e de refugiados ávidos por integrarem-se à sociedade brasileira, mas que não possuem recursos financeiros para custear seus estudos em uma instituição privada (BALZAN; VIEIRA; PEDRASSANI, 2019).

A crescente demanda pelo Curso de Língua Portuguesa para imigrantes e refugiados nos desafia, enquanto docentes e instituição, a pensar em formas de melhor atender esse público, uma vez que há grande probabilidade que as migrações sejam uma realidade constante no Brasil. Além das dificuldades impostas pela língua, existe a diferença entre os sistemas de ensino dos diferentes países e as diversas necessidades de aprendizagem apresentadas por parte dos estudantes. Essas dificuldades já se fazem sentir no sistema de ensino regular, em que imigrantes e refugiados em idade escolar estão sendo matriculados nas escolas públicas de Educação Infantil e Ensino Fundamental do município, e os professores e equipes diretivas não estão se sentindo capacitadas para atendê-los satisfatoriamente. Esse fato repercute, além da falta de iniciativa do poder público em oferecer capacitação para esses profissionais, na própria formação docente, pois ainda são poucos os cursos de licenciatura ou especializações na área da Educação e Letras que abordam a questão do ensino de língua para imigrantes e refugiados.

Entretanto, ao mesmo tempo, esses desafios nos motivam a elaborar estratégias de ensino aliadas a material didático-pedagógico que facilitem o processo de ensino $e$ aprendizagem, que promovam a autonomia desses sujeitos para que se integrem à sociedade brasileira com dignidade e, principalmente, que auxiliem na construção de sua cidadania, para que possam acessar os seus direitos e cumprir os seus deveres, em uma relação baseada no respeito às diferentes culturas. Por isso, os docentes envolvidos no Curso de Língua Portuguesa para imigrante e refugiados estão constantemente desenvolvendo pesquisas 
sobre língua de acolhimento e estratégias de ensino eficazes para esse público específico. Além disso, pensando na formação docente, o Curso de Licenciatura em Letras do IFRSCampus Bento Gonçalves, dentro da disciplina de Estágio Supervisionado - Projetos de Extensão, oportuniza aos licenciandos a experiência com o ensino de língua portuguesa para imigrantes e refugiados através do planejamento e execução de atividades práticas junto ao Curso de Extensão.

\section{Considerações finais}

A demanda por cursos de língua portuguesas para imigrantes e refugiados é uma realidade no contexto brasileiro. Trata-se de uma demanda crescente que tende a se aprofundar ainda mais com pedidos de naturalização requeridos por esses imigrantes que pretendem, agora, estabelecer-se definitivamente em nosso território. Frente a essa realidade, a ação de extensão aqui relatada representa uma iniciativa de bastante êxito, tendo em vista o quantitativo de estudantes atendidos e o baixo índice de evasão que vem sendo conquistado.

Ao ofertar o Curso de Língua Portuguesa para imigrantes e refugiados, o IFRS Campus Bento Gonçalves, muito mais do que simplesmente oportunizar o aprendizado de uma língua essencial para o exercício da cidadania pelo público atendido, está também garantindo acesso a uma educação pública e gratuita que é inclusiva, ao abrir as portas para um grupo social que se encontra, de modo geral, à margem. Além disso, cabe salientar que ao adotar uma perspectiva de ensino de língua portuguesa enquanto língua de acolhimento, o curso contribui para a promoção da formação integral desses cidadãos para enfrentar e superar desigualdades e construir uma vida digna. Que a experiência aqui relatada possa inspirar tantas outras que buscam fortalecer o compromisso social dos Institutos Federais.

\section{Referências}

AMADO, R. S. O ensino de português como língua de acolhimento para refugiado. Revista SIPLE - Sociedade Internacional de Português Língua Estrangeira, v. 7, 2014. Disponível em: http://www.siple.org.br/index.php?option=com_content\&view=article\&id=309:0-ensinode-portugues-como-lingua-de-acolhimento-para-refugiados\&catid=70:edicao7 fltemid=113. Acesso em: 02 jul. 2019. 
BALZAN, C. F. P.; VIEIRA, L. R.; PEDRASSANI, J. S. Língua Portuguesa como passaporte para a cidadania: estudo de caso com imigrantes haitianos no IFRS-Campus Bento Gonçalves. $\begin{array}{llllll}\text { Muiraquitã, } & \text { v. } & 7, \quad \text { n. } 2019 . & \text { Disponível em: }\end{array}$ https://periodicos.ufac.br/index.php/mui/article/view/2894/2025. Acesso em: 17 mar. 2020.

BARRANTES, M. V. Língua adicional e integração? Análise de duas propostas de curso de língua adicional no Brasil e na Alemanha para reflexão de temas e novas possibilidades levando em conta os recentes fluxos migratórios. Revista do PPGL, Faculdade de Letras PUC, RS. Porto Alegre, v. 6, n. 2, 2015. Disponível em:

http://revistaseletronicas.pucrs.br/ojs/index.php/belt/article/view/22949. Acesso em: 04jul. 2019.

BENTO GONÇALVES. Prefeitura inicia trabalho pioneiro na saúde de imigrantes haitianos. Assessoria de Comunicação Social. 2019. Disponível em: http://www.bentogoncalves.rs.gov.br/noticia/prefeitura-inicia-trabalho-pioneiro-na-saudede-imigrantes-haitianos-. Acesso em: 17 mar. 2020.

COSTA, Eric Júnior. Migração e aquisição de Português como Língua de Acolhimento: promovendo a abertura para a diferença e diversidade no Brasil. Anais... V Simpósio de Pesquisa sobre Migrações. Caderno de Resumos. Universidade Federal do Rio de Janeiro (UFRJ), 2017.2 Disponível em: https://forumdeimigracaodotorg.files.wordpress.com/2018/07/e-book-v-simpc3adsio-demigrac3a7c3b5es-2017.pdf. p. 243-248. Acesso em: 03 jan. 2020.

GROSSO, Maria José dos Reis. Língua de acolhimento, língua de interação. Horizontes de Linguística Aplicada, v. 9, n. 2, 2010, p. 61-77. Disponível em: http://periodicos.unb.br/index.php/horizontesla/article/view/886. Acesso em: 15 maio 2019.

POLÍCIA FEDERAL. Ministério da Justiça e Segurança Pública. Naturalização. Disponível em: http://www.pf.gov.br/servicos-pf/imigracao/naturalizacao. Acesso em: 26 set. 2019.

SÃO BERNARDO, Mirelle Amaral de. Português como língua de acolhimento: um estudo com imigrantes e pessoas em situação de refúgio no Brasil. 2016. 206 f. Tese (Doutorado) Programa de Pós-Graduação em Linguística, UFSCar: São Carlos, 2016. Disponível em https://repositorio.ufscar.br/handle/ufscar/8126?show=full. Acesso em: 12 jun. 2019.

Data de submissão: 30/03/2020. Data de aprovação: 30/04/2020. 